\title{
Influence of Unbalanced and Waveform Voltage on the Performance Characteristics of Three-phase Induction Motors
}

\author{
Enrique Quispe ${ }^{1}$, Gabriel Gonzalez ${ }^{1}$ and Jair Aguado ${ }^{1}$ \\ ${ }^{1}$ Grupo de Investigación en Energías GIEN-UAO \\ Departamento de Energética y Electrónica \\ Universidad Autónoma de Occidente \\ Campus Valle del Lili, Calle 25 No.115-85 Km.2 Vía a Jamundí \\ Cali - Colombia \\ phone:+572 3188000, fax:+572 5553911, e-mail: ecquispe@cuao.edu.co, jaguado@cuao.edu.co
}

\begin{abstract}
This paper examines the proper application of three-phase induction motors when supplied by unbalanced and harmonics voltage. The proposed is show that a poor power quality voltage have bad effects over the motor performance: loss, temperature rise, rated horsepower, efficiency, magnetic noise and reliability. Finally this paper present recommendations in order to increase the reliability of inductions motors operations.
\end{abstract}

\section{Key words}

Induction motors, unbalance, harmonics, voltage, performance characteristics.

\section{Introduction}

Motor-driven systems use two-thirds of the total electricity consumed by industry. By other side the increasing emphasis on overall power system efficiency has result in a continued growth in the application of devices such as high-efficiency, adjustable-speed motor drives and shunt capacitor for power factor correction to reduce loss. This is resulting in increasing harmonic levels on power system. Being the induction motor the most popular one in the industry, it is very important to carry out studies about the effects of power quality in the efficiency and reliability of three-phase induction motors.

The paper present the proper application of three-phase induction motors when supplied by unbalanced and harmonics voltage, the effects of unbalanced voltage and harmonics voltages over efficiency and other operations characteristics are presented. The proposed is show that a poor power quality voltage have bad effects over the motor performance: loss, temperature rise, rated horsepower, efficiency, magnetic noise, current in bearings and reliability. Finally this paper present recommendations in order to increase the reliability of inductions motors operations.

\section{Influence of Unbalanced Voltage}

When the line voltages applied to a three-phase induction motors are no equal, unbalanced currents in the stator windings will result. The effect of unbalanced voltages on induction motors is equivalent to the introduction of a "negative-sequence voltage" having a rotation opposite to that occurring with balanced voltages. This negativesequence voltages produces an air gap flux rotating against the rotation of the rotor, tending to produce high currents.

Each set of positive and negative sequence voltages produce corresponding balanced currents in the induction motors and the synthesis of the two sets of current vectors represents the actual currents produced in the three stator phase by the original unbalanced voltages.

The behaviour of the machine to the positive sequence voltage is essentially the same as normal balanced operation. The negative sequence currents, however set up a reverse field, so that if the rotor slip is $s$ with respect to the positive sequence field, it will be $(2-s)$ relative to the negative sequence field. The equivalent circuits of the induction motors for each sequence are presented by many authors, (e.g. [6], [12]). The motor behaves as the addition of two separate motors, one running at slip $s$ with terminal voltage equal to positive sequence voltage and the other running with a slip of (2-s) and a terminal voltage equal to negative sequence voltage. With this model it is easy to see that the flux of negative sequence is running at a speed that is approximately twice the synchrony speed respect to rotor, then the loss in the rotor core are increase significantly.

The equivalent circuit permit to explain why the motor torque is decrease. The positive sequence torque resembles the torque of an induction motor operating from a balanced supply. The counter rotating field produced by the negative sequence currents produces a 
negative torque. The magnitude of the negative sequence is not negligible, so that the net shaft torque produced by the machine will be somewhat less than that produced by balanced supplied.

\section{A. Definitions of Voltage Unbalance}

The definition of voltage unbalance used by academic community is the ratio of the negative sequence voltage $V_{a b 2}$ to the positive sequence voltage $V_{a b 1}$.

$$
\% \text { voltage unbalance }=\frac{V_{a b 2}}{V_{a b 1}} * 100
$$

This definition is adopted by IEC 60034-26, [8].

For a set of unbalanced voltages, $V_{a b}, V_{b c}, V_{c a}$ the positive and negative sequence voltages $V_{a b 1}$ and $V_{a b 2}$ are given by

$V_{a b 1}=\frac{V_{a b}+a * V_{b c}+a^{2} * V_{c a}}{3}$

$V_{a b 2}=\frac{V_{a b}+a^{2} * V_{b c}+a * V_{c a}}{3}$

where $a=-0.5+j 0.866$ and $a^{2}=-0.5-j 0.866$

However the NEMA Standard MG1.1993 and the IEEE community use the following definition:

maximum voltage deviation
$\%$ unbalance $=\frac{\text { deviation from average voltage }}{\text { average voltage }} * 100(2)$

NEMA definitions avoid the use of complex algebra. However both definitions give different results.

For example if the three unbalanced line to line voltages are:

$V_{a b}=450 \angle 0^{\circ}, V_{b c}=363.6 \angle-121.44^{\circ}, V_{c a}=405 \angle 130^{\circ}$

Then the positive sequence voltage $V_{a b 1}$ is $404.625 \angle 2.89$ and the negative sequence voltage $V_{a b 2}$ is $50.217 \angle-23.98$. Then using the IEC definition, equation( 1$)$, the $\%$ unbalance is :

$\%$ voltageunbalance $=\frac{50.217}{404.625} * 100=12.41 \%$

But if we use the NEMA definition, equation (2), the average voltage is 406.2 and the maximum voltage deviation from average voltage is $450-406.2=43.8$. Then the $\%$ unbalance is:

$\%$ voltageunbalance $=\frac{43.8}{406.2} * 100=10.78 \%$

Then we observed that there are a different results when we use each one of definition. An extensive analysis made by Pillay [12], revealed that the differences in the definitions do not result significant differences when operated by unbalanced supplies in the $5 \%$ range.

\section{B. Effects on Rated Horsepower}

A small percentage voltage unbalance will result in a much larger percentage current unbalance, then the temperature rise of the motor operating at a particular load and percentage voltage unbalance will be greater than for the motor operating under the same conditions with balanced voltages.

Voltages preferably should be evenly balanced as closely as can be read on a voltmeter. Should voltages be unbalanced, the rated horsepower of the motor should be multiplied by the factor shown in Fig. 1 to reduce the possibility of damage to the motor. If the unbalance is $1 \%$ there is not problem, if the unbalance is $2 \%$ the derating factor will be 0.96 , but if the unbalance is $5 \%$ the derating factor will be 0.76 . Then the operation of the motor above a 5-percentage voltage unbalance condition is not recommended.

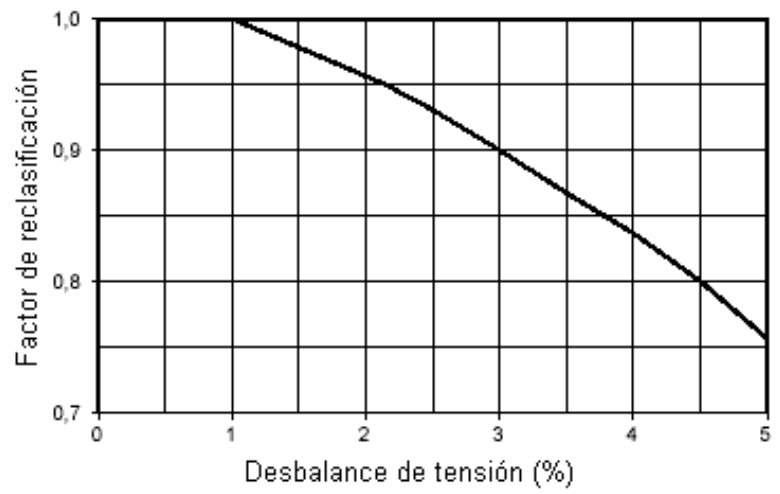

Fig.1 Derating of Rated Horsepower.

\section{Effects on others Operations Characteristics}

In previous works, several authors and organism ([3],[6],[8],[11]) given the negative effects of unbalanced voltage on operations characteristics.

The locked-rotor and breakdown torque are decreased when the voltage is unbalanced, then if the voltage unbalance should be extremely severe, the torques might not be adequate for the application.

The full-load speed is reduced slightly when the motor operates at unbalanced voltages.

The locked- rotor current will be unbalanced to the same degree that the voltages are unbalanced, but the lockedrotor KVA will be increase only slightly.

The currents at normal operating speed with unbalanced voltages will be greatly unbalanced in the order of approximately 6 to 10 times the voltage unbalance. 


\section{Influence of Waveform Voltage}

When the waveform voltage supplied to induction motors is distortion then the wave voltage have harmonics voltages components. Harmonic voltage distortion at the motor terminals is translated into harmonic fluxes within the motor. Harmonic fluxes do not contribute significantly to motor torque, but rotate at a frequency different than the synchronous frequency, basically inducing high-frequency currents in the rotor. Thus, the harmonics voltages influence on loss, temperature rise, rated horsepower, efficiency and life time of bearing .

By other side, harmonics currents are introduced when line voltages applied to a induction motor include harmonics voltages components.

The speed of the synchronous rotating field of the induction motor stator is $(4 \pi / p) f_{1}$ where $\mathrm{p}$ is number of poles and $f 1$ is the rated frequency. For a $\operatorname{slip} s$, the rotor speed is thus $(4 \pi / p) f_{1}(1-s)$ and the frequency of the rotor currents is $s f_{1}$.

The harmonics of stator currents produce harmonics of $m . m . f$. and these induce other harmonics in the rotor depend of speed. Thus:

A harmonic of order $n$ in the rotor m.m.f. travels at a speed $\left.\pm(4 \pi / p) s f_{1} / n\right)$ with respect to the rotor. And travels at a speed $\left.(4 \pi / p) f_{1}(1-s) \pm(4 \pi / p) s f_{1} / n\right)$ with respect to the stator. This harmonic induces an e.m.f. in the stator at a frequency equal to $f_{1}\{n-s(n \pm 1)\}$, the positive sign being taken when the harmonic rotor m.m.f. travel in the opposite direction to the fundamental.

\section{A. Definition of Harmonic Voltage Factor (HVF)}

The harmonic voltage factor (HVF) is defined as follows:

$$
H V F=\sqrt{\sum_{n=5}^{n=\infty} \frac{\left(V_{n}\right)^{2}}{n}}
$$

Where:

$n=$ order of odd harmonic, not including those divisible by three.

$V_{n}=$ the per-unit magnitude of the voltage at the $n$th harmonic frequency.

For example if the line voltage have harmonics voltages component with per-unit voltages of $0.10,0.07,0.045$ and 0.036 ocurring at the $5,7,11$, and $13^{\text {th }}$ harmonics, respectively, the value of the $\mathrm{HFV}$ is:

$$
H V F=\sqrt{\frac{0.1^{2}}{5}+\frac{0.07^{2}}{7}+\frac{0.045^{2}}{11}+\frac{0.036^{2}}{13}}=0.0546
$$

The definition about the HVF give in the NEMA Standard MG1 [9], is the same that the HVF definition give by IEC [7].

\section{A. Effects on Temperature Rise and Rated Horsepower}

The effect of harmonics on motor losses should consider the subdivision of losses into windage and friction, stator copper loss, core loss, rotor copper loss, and stray loss in the core and conductors, and the effect of harmonics on each of these components.

The effective rotor and stator leakage inductance decrease and the resistance increases with frequency. The rotor resistance may increase four to six times dc value while leakage reactance may reduce to a fraction of the fundamental frequency value. The stator copper loss increases in proportion to the square of the total harmonic current plus an additional increase due to skin effect at higher frequencies. Major loss components influenced by harmonics are stator and rotor copper loss and stray losses.

The increase in losses will also result in an increase in motor temperature and a decrease in the rated horsepower of motor. To avoid motor overheat, its rated horsepower should be also reduce so as to maintain the temperature within thermal class limits.

According to NEMA MG1.1993 Part 30 [11], it is possible to relate motor horsepower reduction, called Derating Factor (DF), with $H V F$ in the graphic of figure 2.

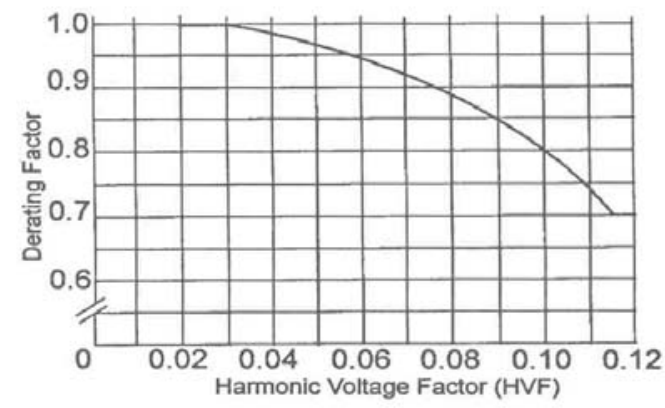

Figure 2. Derating Factor with HVF

If the voltage supplied to induction motors have a HVF equal to $3 \%$ there is not problem, if the HFV is $5 \%$ the Derating Factor $(D F)$ will be 0.97 , but if the HVF is $11 \%$ the $D F$ will be 0.75 then the horsepower will de reduce in $25 \%$. Then the operation of the motor with a VHF above $5 \%$ is not recommended.

\section{B. Effects on the Efficiency}

The efficiency of an induction motor when the voltage supplied have harmonics voltages components is reduced due to increase in loss caused by harmonics currents present in the motor winding. In order to estimate new efficiency of the motor as a function of the Derating Factor, the following formula is used. 


$$
\eta_{c}=\frac{D F^{2}}{\frac{1}{\eta}+D F^{2}-1}
$$

$\eta$ is the motor efficiency used on a sinusoidal bus.

$\eta_{c}$ is the motor efficiency when the voltage supplied to motor have harmonics components.

\section{Effects on Bearing Due to Bearing Currents}

There are at least three mechanisms of bearing current generation, each mechanism may or my not occur, depending on the bearing electrical characteristics. The mechanism are: bearing current due to discharge of airgap capacitor, bearing current due to $d v / d t$ in common -mode voltages, and circulating bearing current due to magnetic flux resulting from zero sequence harmonics currents. The first two mechanisms are directly relate to the common-mode voltage and appear when the motor is operated by pulsewidth modulation (PWM) inverters. In this paper we only explain the third mechanism.

The zero sequence harmonics currents, $n=0,3,6$, 9, etc. have a same characteristic, they come from the three motor input terminals and are in phase in the time. Therefore, the sum all three phase currents supplied to the motor must not be zero, but equal to the total zero sequence current. This zero sequence currents will be produce a net flux enclosing the motor shaft. Consequently, a back e.f.m. will be induced in the conductive loop formed by the shaft, the bearing and the stator enclosure, as show in Figure 3. The e.f.m. is usually very small, in the millivolt range, however when the impedance of this loop is sufficiently low, a circulating current will pass through the bearings.

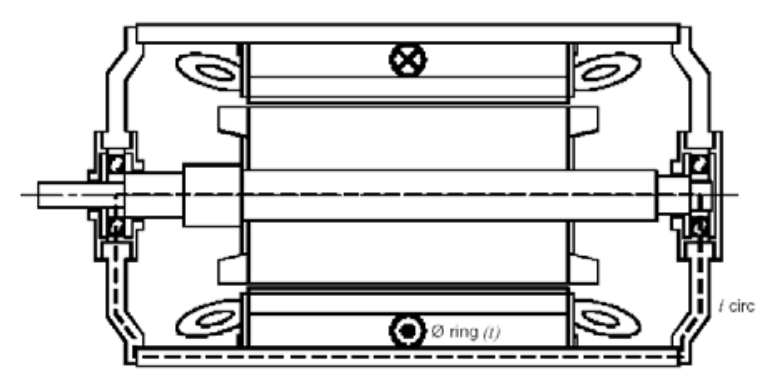

Fig. 3. Path of circulating bearing currents due to flux linkage caused by zero sequence harmonics current.

A study realized by Macdonal [4] say that if shaft voltages exceeding $300 \mathrm{mV}$ require one bearing of the motor to be insulated to prevent circulating current damage to the bearing. Normally the opposite drive end (ODE) bearing is chosen, because if the drive end (DE) is insulated, the load can provide an electrical path that completes the loop to allow current to flow.

\section{Conclusion}

In order to calculate the horsepower derating of motor produced by unbalanced voltage, it is advise to apply the IEC equation to calculate de percentage unbalanced voltage. However the differences in the definitions do not result in significant derating differences when operated by unbalanced supplies in the $5 \%$ range.

It is not recommended the operation of the induction motor above $2 \%$ of voltage unbalance. If the unbalance voltage is above $2 \%$ the rated horsepower must be derated. It is dangerous to the motor if the unbalanced voltage is $5 \%$ or more.

The unbalanced currents could be caused also by a rotor problem. But if the rotor is good, in the locked-rotor test, the locked-rotor current will be unbalanced to the same degree that the voltages are unbalanced.

It is not recommended the operation of the induction motor if the HFV is more than 5\%. If the HFV above 5\% then the rated horsepower must be derated. Remember that with a HVF of $11 \%$ rated horsepower will be reduce in $25 \%$.

Shaft voltages exceeding $300 \mathrm{mV}$ require one bearing of the motor to be insulated to prevent circulating current damage to the bearing. It is strongly recommended to use the opposite drive end (ODE) bearing.

\section{Acknowledgement}

The authors acknowledge the support from "Vicerrectoria de Investigaciones" of the "Universidad Autonoma de Occidente" during the progress of this work.

\section{References}

[1] A. Bonnett, " Quality and Reliability of Energy Efficient Motors", IEEE Industry Applications Magazine, Vol.3, No.1,pp. 22-31, January/February. 1997.

[2] B. Hugh, "Bearing Fluting", IEEE Industry Applications Magazine. Vol.8, No.5, pp 53-57, September/ October 2002.

[3] EPRI “ Voltage Unbalance: Power Quality Issues, Related Standards and Mitigation Techniques" Final Report, June 2000, California, USA.

[4] D. Macdonald and W. Gray, " PWM Drive Related Bearing Failures", IEEE Industry Applications Magazine, Vol. 5, No.4, pp. 41-47, July-August 1999.

[5] E. Quispe, "Efecto de la Calidad de la Potencia Eléc.trica en la Operación de los motores de Inducción" Memorias II Simposio Internacional sobre Calidad de 
Energía Eléctrica SICEL2003, Unidad Publicaciones, Facultad Ingeniería, Universidad Nacional de Colombia, pp. 103-107, November 2003, Colombia.

[6] E.Quispe and J. Pretel J "Modelo Matemático para el Análisis en Estado Estable del Motor de Inducción con Asimetrías en el Estator y Rotor", Revista El Hombre y la Máquina-CUAO, No. 13, pp. 87-97. Cali- Colombia, 1998.

[7] International Electrotechnical Commission, Rotating Electrical Machines : Part 17 (IEC 60034-17) Guide for Application of Cage Induction Motors when Fed from Converters, Geneve: IEC 2002,35 p.

[8] International Electrotechnical Commission, Rotating Electrical Machines : Part 26 (IEC 60034-26) Effects of Unbalanced Voltages on the Performance of Induc tion Motors, Ginegra: IEC 2002,15 p.

[9] J. Das, Power System Analysis : Short-Circuit Analysis and Harmonics , Marcel Dekker, Inc., New York (2002), pp.597-603.

[10] J. Arrillaga, D. Bradley and P. Bodger, "Power System Harmonics", John Wiley \& Sons, New York (1985), pp.103- 116.

[11] NEMA, Standard Publications No. MG1-1993. Motors and Generators, Published by National Electrical Manufacturers Association, Washington (1993), Part 21 pp. 9 - 10 and Part 30 pp. 1- 2.

[12] P. Pillay, “ Derating of Induction Motors Operating with a Combination of Unbalanced Voltages and Over or Undervoltages", IEEE Transactions on Ener gy Conversion, Vol. 17, No.4, pp. 485-491, December 2002 .

[13] R. Dugan, Electrical Power System Quality, Mc Graw-Hill, New York (1996), pp.2-7, 154- 155.

[14] S. Chen and T. Lipo, “Bearing Currents and Shaft Voltages of an Induction Motors Under Hard- and Soft-Switching Inverter Excitation.”, IEEE Transactions on Industry Applications, Vol. 34, No.5, pp. 1042-1048, September/October 1998. 